\title{
Socio-demographic and lifestyle determinants of loyalty program participation in the Czech Republic
}

\author{
Tomáš FORMÁNEK \\ University of Economics, Prague, Faculty of Informatics and Statistics, University of \\ Economics, Prague, Czech Republic \\ Radek TAHAL \\ University of Economics, Prague, Faculty of Business Administration, University of \\ Economics, Prague, Czech Republic \\ radek.tahal@vse.cz
}

\begin{abstract}
Loyalty programs are among the most frequently employed marketing tools used to minimize customer attrition rates. In this article, different aspects of consumer participation in loyalty programs for major product categories are analyzed with focus on generational differences. We use the time-proven segmentation of Baby boomers and generations $X, Y$ and $Z$. Our analyses and findings are based on primary data (2016): the survey is formed by a representative sample of 585 respondents. A wide portfolio of statistical learning methods and tests is used for data analysis. The first segment of our analysis brings forward groups of product categories where consumers tend to use loyalty programs concurrently. This identifies opportunities and boundaries for establishing and managing co-branded loyalty programs. The second part of our quantitative analysis is based on generational, other socio-demographic and lifestyle factors influencing individual participation in loyalty programs. Here, the main focus is on four product categories where loyalty programs are used most often. Generational differences are well pronounced in fashion-related categories. On the other hand, loyalty program usage rates in product categories related to basic household operations show little generational differences.
\end{abstract}

Keywords: Loyalty program, customer retention, market research, FMCG, product category, generational aspects.

Please cite the article as follows: Formánek, T. and Tahal, R. (2017), "Socio-demographic and lifestyle determinants of loyalty program participation in the Czech Republic", Management \& Marketing. Challenges for the Knowledge Society, Vol. 12, No.4, pp. 524-539, DOI: 10.1515/mmcks-2017-0031.

\section{Introduction}

The requirements put on contemporary marketing operations are higher than they used to be in the past. Marketers are expected not only to devise advertising and communication campaigns and to participate in strategic and tactical decisions on product development, but also to set up and manage channels to strengthen relationship with existing customers. "Nowadays many organizations have replaced product orientation with customer orientation and improving the quality of goods and services to further their customer satisfaction" (Pourmand and Lari, 2016).

Loyalty marketing is a discipline that is gaining growing importance. However, this complex discipline requires an ever better and deeper understanding of consumer behavior in an evolving market environment. Loyalty marketing tools are 
particularly important for product categories where we can expect re-purchases, perhaps frequent. A loyalty program (LP) is a popular marketing tool, specifically designed to maintain relationships with existing clients. From a business perspective, the main mission of an LP is to increase turnover and profit. For customers registered in an LP, retailers can easily track purchasing habits: what products individual customers buy, in what combinations and how frequently. To actually deliver on the long-term re-purchases sought after, different parameters and features of the LPs are set up and repeatedly adjusted to provide incentives and motivation drivers for customers. We refer here to the so-called longitudinal function (Yoo, 2011), defined as a long-term partnership at the individual customer level. Different studies reflect on the effectiveness of investments into relationship marketing tools and the positive impact of LPs on the so-called share of wallet (e.g. Meyer-Waarden, 2008). At the same time, possible negative effects of dilution by third party LPs should be considered (e.g. Macías and Cerviño, 2017).

LPs provide benefits to both sides involved: customers get different types of rewards for their participation and loyalty while the retailers gain on the sales level and obtain valuable information. Data collected from LPs are used for segmenting consumers, managing marketing communication tools, in CLV (customer lifetime value) calculations, etc. However, the above discussed mutual benefits may only take place after consumers become LP members. Hence, for marketers, it is crucial to understand the general patterns and consumers' generational structure, sociodemographic characteristic, lifestyle preferences and attitudes towards LP participation: such information may serve to amend LP terms, e.g. in order to attract more LP participants. Importantly, data for such attitude analysis cannot be gathered from LP members only, the whole consumer population needs to be sampled for unbiased results.

With those facts in mind, our research focuses on two main topics: (1) analyzing customers' attitudes towards LP participation across different product categories, with an overall emphasis on the generational perspective; (2) identification of clusters of product categories for which consumers tend to participate in LPs concurrently.

The rest of this paper is structured as follows: next section provides literature overview and it is followed by methodology-related topics. Empirical results and their detailed analysis are followed by the concluding section and the list of references.

\section{Literature review}

At the beginning of the 1970s, Jacoby (1973 cited in DuWors and Haines, 1990) provided a comprehensive definition of loyalty: "Brand loyalty is a biased (i.e. nonrandom), behavioral response (i.e. purchase), expressed over time, by some decision-making unit, with respect to one or more alternative brands out of a set of such brands, and is a function of psychological processes". In the mid-1990s, massivescale LPs were started by supermarket chains (Rowley, 2007). Over time, marketing professionals became increasingly aware of the fact that loyal customers are much more than satisfied customers. "Truly loyal customer add value to a firm by serving as a beacon to guide corrective action. When a firm fails to provide adequate service, 
disloyal customer defect, loyal customers are willing to remain and provide feedback" (Craft, 1999).

Customer loyalty is closely related to brand equity. "Brand equity is a set of brand assets and liabilities linked to a brand, its name and symbol, that add to or subtract from the value provided by a product or service to a firm and/or to that firm's customers" (Aaker, 2009). The impact of customer loyalty and confidence in a brand on the overall corporate performance is addressed in numerous studies (e.g., Chaudhuri and Holbrook, 2001). Other authors point out that "loyal behavioral intention towards the parent brand is important for achieving a positive evaluation" (Hem and Iversen, 2002).

LPs mostly reward customers on the base of their buying history. "A loyalty program is an integrated system of marketing actions that aim to reward and encourage customers' behavior and attitudes through incentives" (Maity and Gupta, 2016). "Reward is one of the loyalty programme service quality dimensions and is defined as the extent to which cardholders perceived that the loyalty card programme offers high quality and desirable rewards to cardholders." (Omar, et al., 2013).

Customer segmentation is an ever more important tool for establishing adequate marketing mix. Human life cycle forms the base of a frequently used and well-founded approach to segmentation. "Marketing researchers have adopted the life cycle concept to study consumer needs and spending patterns. In contrast to life cycle research in sociology typically focuses on the family" (Bauer and Auer-Srnka, 2012). Increasingly, segmentation from the generational point of view is also applied. "Generational difference in consumption is closely related to the consumer predicted values" (Shahzad, et al., 2015). Many authors (e.g. Roy, Guha and Biswas, 2015) speak of the so-called "generational cohorts". Williams, et al., (2010), elaborate on multigenerational marketing and state that: "Marketers also need to build relationships with each specific generation represented in their target audience or community". The knowledge of generational specificities is an important input variable that is used to establish corporate strategies and brand positioning. Numerous studies have shown that members of younger generations of consumers are more economical, more responsible and more demanding than traditional (older) consumers (Voinea et al., 2015).

"Among the many demographic groups of consumers, Generation Y represents a young, technology-savvy group. Having grown up with the internet, Generation Y consumers are heavy users of SNS [social networking sites], and social media in general play a huge role in how they live and interact with others." (Bilgihan et al., 2014). Many related studies deal with the $Y$ generalization as an emerging generation of consumers that will determine future trends in a significant way. For example, Loroz and Helgeson (2013) state: "Gen Y also show a greater propensity for selfmonitoring, product categories that are subject to high levels of peer influence and group affirmation (e.g. footwear, jeans, mobile phones, high-tech gadgets, sports equipment, fast food, and beverages) are likely to be particularly salient to this generation". Of course, many authors pay attention to generations $\mathrm{Z}$ and X as well. For example, Roberts and Manolis (2000) say: "One factor that seems to accurately distinguish the $\mathrm{X}$ generation from other generations is its preoccupation with material possessions and shopping".

Vol.12, No.4,Winter, pp. 524-539, ISSN 1842-0206| Management \& Marketing. Challenges for the Knowledge Society 
Customer retention is a major profit driver in today's saturated market environment. Companies invest substantial amounts of human and financial capital to establish and manage LPs and similar loyalty schemes aimed at customer retention. Besides retaining customer portfolios, LPs are used as complex data sources for marketing operations. Customers' personal data (e.g. Tahal et al., 2017) and their LPbased shopping records may serve for many purposes: from customized direct mailing (tailored gifts and discounts, follow-up offers), to complex quantitative analyses of customer behavior, product portfolio optimization tasks, etc.

\section{Research methodology \\ Research focus}

This article focuses on socio-demographic and lifestyle factors that influence individual willingness to participate in a loyalty program. Major focus is devoted to age-based differences in LP participation, with particular focus to the so-called generations $\mathrm{X}, \mathrm{Y}, \mathrm{Z}$ and the post-WW2 Baby boomers. Besides generational differences, we pay close attention to other socio-demographic factors (gender, domicile) as well as lifestyle activities of the respondents. This corresponds to the work of Chung and Hsu (2012), who emphasize the importance of quantified lifestyle factors knowledge for market segmentation tasks and for developing marketing strategies.

Overall, our efforts may be summarized using the following two main research topics/goals: Goal 1: Comparison and analysis of LP participation ratios for different product categories and LP-based clustering analysis. Goal 2: Quantitative analysis of LP-participation driving factors with focus on generational aspects (for different product categories).

\section{Data handling}

For the evaluation of socio-demographic and lifestyle factors that influence LP participation by consumers, we use the following twelve product categories where LPs are used most often: (a) Food \& beverages, (b) Drugstore, (c) Clothing, (d) Shoes, (e) Electronics, (f) Home, (g) Cinema, (h) Restaurant, (i) Hobby \& garden, (j) Toys, (k) Small home appliances, (l) Master home appliances. This classification is based on corporate retail audit practices, yet it has a reasonable support in relevant literature as well (Oliver, 1999).

Our research is based on primary data for the Czech Republic: from April 2016 to November 2016, the population of retail consumers (age 15+) was surveyed. In a stratified/quota sampling process, a total of 585 complete and properly filled survey forms were collected by means of personal and on-line data collection channels. Complex survey forms were used to collect anonymized data on respondent's sociodemographic status, lifestyle activities, general preferences in a wide range of work and leisure activities (including self-positioning), consumer habits and attitudes across different product categories, personal data and privacy awareness, etc. Different types of questions were used in the survey: qualitative (Yes/No), Likert scale (different degree spans) and quantitative (mostly interval-based).

The survey was organized and performed by researchers at the University of Economics, Prague. The research team was led by university employees and teachers Vol. 12, No. 4, Winter, pp. 524-539, ISSN 1842-0206 | Management \& Marketing. Challenges for the Knowledge Society 
who coordinate and supervise the work of students specializing in marketing research. This study is part of a long-term project of systematic surveys and analyses of consumer behavior (e.g. Formánek and Tahal, 2016 and Tahal et al., 2017). The quantitative analysis (logistic regression and related tests and methods) is adjusted to control for stratified/quota sampling. Hence, our methodology ensures interpretability of the results and conclusions may be drawn with respect to the population. The "Runs" test and similar data-validation procedures were used to test for potential survey mishandling (Gibbons and Chakraborti, 2003).

For subsequent quantitative analysis, data gathered from the questionnaires were recorded using binary indicators. The transformation of Yes/No questions (e.g. LP-participation in a given product category) into $1 / 0$ data is clear-cut. For intervalbased quantitative variables such as age or personal income, binaries are used to express the corresponding interval entry. For example, respondent's age is recorded using the following generational categories (i.e. variables representing individual affiliation with a particular age interval): $g e n_{-} Z_{i}=1$ for generation $Z$ members (i.e. if the i-th individual is 15-24 years old) and it equals 0 otherwise. Similarly, gen_ $Y_{i}$ is used to identify generation $Y$ members (ages 25-34), gen $X_{i}$ is used for generation $X$ (ages 35-49) and $B B+_{i}$ identifies Baby boomers and older individuals (aged 50 or more). The surveyed Likert scale answers (i.e. ordered multinomial data) are also recorded using binary variables. For example, respondents were presented with a statement "I do sports/fitness/gym activities" and asked to position themselves towards this statement using a 5-degree Likert scale ("1" = this statement describes me very well, ... , "5" = this statement doesn't describe me at all). Mostly subjective perception of individual's lifestyle is expressed here, rather than the actual time or money spent at the activity. Please note that following sports (i.e. rooting for a football club) is addressed by a different survey question. Also, Likert scale data bear ordinal meaning only (i.e. " 2 " is better than " 3 ", but the difference between " 1 " and " 3 " is not necessarily twice as large as difference between " 4 " and " 5 "). Hence, the surveyed answers to the example question were used to produce two binary variables: LSfitnessYes $_{i}=1$ for individuals who answer "1" on the Likert scale and LSfitnessNo ${ }_{i}=$ 1 for those who answer " 5 ". Based on empirical experience, we combine all the remaining answers ("2" to "4" - i.e. not a very strong position on the subject) into a single reference category. This is a very convenient approach: all cases where respondents have a strong position are retrieved while keeping the dataset simple, the reference category remains an implicit part of the analysis and LSfitnessYes and LSfitnessNo variables are linearly independent and can be both included as explanatory variables in a single regression model (at least in theory).

\section{Quantitative methods}

Using the above described approach, we have generated a 585-row and 140-variable (column) dataset from the surveyed questionnaires. Twelve of the 140 variables are the dependent binary variables that describe LP participation across product categories. For example, FoodBev $_{i}=1$ if the $i$-th individual participates in a LP for the (a) Food \& beverages category (and it equals zero otherwise). Besides the main-focus generational aspects, we need to identify and properly quantify the influence of other potentially important factors influencing LP participation (such as gender, etc.). For

Vol. 12, No.4, Winter, pp. 524-539, ISSN 1842-0206| Management \& Marketing. Challenges for the Knowledge Society 
this purpose, we use a combination of two statistical learning algorithms: forward stepwise selection with sequential replacement and the non-parametric random forest approach (Hastie et al., 2009).

This approach was chosen due to the computationally inaccessible requirements involved in complete (exhaustive) search for the truly optimal specification, which would require an estimation and evaluation of some $12 \times 2128$ models. As a price to pay for computational feasibility, both statistical learning methods used may individually lead to sub-optimal regressor composition of the target model. Therefore, differences in outputs from the two methods were examined to detect any possible discrepancies. Overall, our approach to variable importance evaluation leads to fairly robust results, with a relatively low potential for suboptimality (Hastie et al., 2009). The above described variable evaluation methodology was used to generate a complex model (consistent across product categories), as follows:

$$
\begin{aligned}
y_{i}=\beta_{0}+\beta_{1} & \text { gen_X }_{i}+\beta_{2}{\text { gen_ } Y_{i}+\beta_{3} \text { gen_ }_{i}+\beta_{4} \text { Female }_{i}} \\
& +\beta_{5} \text { Prague }_{i}+\beta_{6} \text { EducUniv }_{i}+\beta_{7} \text { EarningsHigh }_{i} \\
& +\beta_{8} \text { LSnatureNo }_{i}+\beta_{9} L S_{-} T V_{-} N o_{i}+\beta_{10} \text { LSFitnessYes }_{i} \\
& +\beta_{11} \text { LSgreenfingYes }_{i}+u_{i},
\end{aligned}
$$

where $y_{i}$ is a binary dependent variable, describing whether the $i$-th individual participates in a LP for a given product category: twelve different equations are estimated from model (1), for all the product categories established. The RHS binary variables $g e n_{-} X_{i}, g e n_{-} Y_{i}$ and $g e n_{-} Z_{i}$ have been described previously; the age category $B B+{ }_{i}$ is omitted for technical reasons and serves as a reference age level. Female describes respondents' gender (equals 1 for women, 0 otherwise). Similarly, Prague is $_{i}$ used to distinguish respondents living in the capital city. Respondent with a university degree are depicted by EducUnivi (basic and secondary education form a single reference category) and EarningsHigh $h_{i}=1$ for respondents with total monthly household income of CZK 80.000 or more (approx. EUR 3.100+). As for the lifestyle factors, variables $L S n a t u r e N o_{i}$ and $L S_{-} T V_{-} N_{i}$ equal 1 for respondents who strongly dissociate themselves from statements "I like trips/walks in nature" and "I like watching TV" respectively. LSfitnessYes $i$ has been introduced already and LSgreenfing Yes i $_{i}$ describes individuals who associate themselves with hobby gardening (growing fruits/vegetables, lawn mowing, etc.). Finally, $\beta_{j}$ are coefficients of the model and $u_{i}$ is the usual random element (potentially heteroskedastic).

The $\beta_{j}$ coefficients from equation (1) are estimated using the maximum likelihood approach from a logistic function

$\mathrm{P}\left(y_{i}=1 \mid \boldsymbol{x}_{i}^{T}\right)=\exp \left(\boldsymbol{x}_{i}^{T} \boldsymbol{\beta}\right) /\left[1+\exp \left(\boldsymbol{x}_{i}^{T} \boldsymbol{\beta}\right)\right]$

where $\mathrm{P}\left(y_{i}=1 \mid \boldsymbol{x}_{i}^{T}\right)$ is the probability of $i$-th individual's participation in a LP for a chosen product category, given the observed vector of explanatory variables. Expression $\boldsymbol{x}_{i}^{T} \boldsymbol{\beta}$ is the RHS of equation (1) excluding the random element. The nonlinear nature of logistic function (2) ensures that all fitted (expected) probabilities of LP-participation lie within a $\langle 0,1\rangle$ interval. Unfortunately, this nonlinearity also Vol. 12, No. 4, Winter, pp. 524-539, ISSN 1842-0206 | Management \& Marketing. Challenges for the Knowledge Society 
means that the estimated $\beta_{j}$ coefficients are not easily interpretable - except for their signs and statistical significances. The expected effect on LP-participation probability induced by a ceteris paribus change in some $x_{j}$ regressor has to be calculated individually (for each $i$-th consumer). This becomes evident once we take the first derivative along $x_{j}$ of the compound function (2). However, for effective model interpretation, we can summarize the individual effects across the whole sample (averaged changes in expected probabilities). This yields a representative and wellestablished summary statistics: the average partial effects (APEs). In most cases, the APEs are reported along with corresponding standard errors and significance statistics. For detailed discussion of binomial logistic models, their estimation, statistical inference and APE calculation, see Wooldridge (2010).

Focusing on the generational aspects of LP participation, a section of this paper provides an extension of the logistic model (1), where a complete set of Age-Gender interaction terms (for example, gen_ $X_{i} \times$ Female $_{i}$ equals 1 for females belonging to generation $X$ and zero otherwise) is introduced. Interaction terms often provide important additional insight into the dynamics of expected probabilities, however their interpretation within the logistic model environment can be laborious. Hence, we provide an informative visual summary, the so-called effect displays (Fox and Hong, 2009).

The above described methods are supplemented by several other approaches that provide complexity and plasticity to our quantitative analysis and its interpretation. Hierarchical clustering is used to evaluate the "similarity" of LP participation across product categories. Here, similarity of LPs is defined and measured by individual's socio-demographic characteristics, lifestyle preferences and consumer behavior of individuals concurrently participating (or not participating) in different LPs (Gordon, 1999). Finally, some task-specific statistical tests are briefly introduced within the next section as they are used.

\section{Results and discussion}

Our analysis starts with a complex LP-participation rate evaluation. The observed participation rates can be summarized (see Table 1) in descending order, ranging from $47.2 \%$ in the Food \& beverages category to a mere $4.4 \%$ for Master home appliances. This ordering provides just a basic insight into consumer attitudes towards LP usage. Multiple layers of additional evaluation and testing are necessary to provide a complex and actionable insight. The variance of LP-participation ratio is an important, yet rather non-informative indicator: for binomial variables, variance always equals $p(1-p)$ where $p$ is the participation ratio for a given product category. The Equal means column (Table 1) visually summarizes the results of Wilcoxon signed rank tests (matched pairs) that is used to identify product categories with identical participation rates - statistically speaking and using the usual $5 \%$ significance level. The Wilcoxon test is pairwise-defined (Gibbons and Chakraborti, 2003). Therefore, as we identify a common group for Electronic, Home, Cinema and Restaurant product categories, this means that for all 6 possible category pairs within this group, $H_{0}$ of equal means cannot be rejected. In contrast, we may see that Toys, Small home appliances and Master home appliances do not form a single group - the 
participation rates of Toys and Master home appliances are different at the $5 \%$ significance level.

As we identify product categories with equal participation rates, we need to be aware that identical participation rates might be generated by less-than-identical respondent groups (statistically speaking). In fact, socio-demographic or otherwise defined consumer groups participating in LPs for different product categories are often only weakly overlapping and may be almost mutually exclusive. To address this issue, we calculate pairwise correlations among the binaries describing LP participation across product categories. To save space and keep this contribution easily accessible to readers, we omit the corresponding output table - it may be obtained from the authors upon request, along with other supplementary output materials and $\mathrm{R}$ codes used for estimation. We do not find any negative correlations in our sample, hence there is no evidence of mutual exclusivity among LP-participation at the individual level. This is an important finding as we have somewhat expected certain levels of negative correlations in product category pairs such Hobby \& garden vs. Electronics or Cinema. Typical pairwise correlations range from +0.10 to +0.35 with an exception of Drugstore, Food \& beverages, Clothing and Shoes product groups that are pairwise-correlated in the range of +0.45 to +0.55 .

Table 1. LP participation summary

\begin{tabular}{|l|c|c|c|c|c|c|}
\hline & $\begin{array}{c}\text { LP members } \\
\text { (out of 585 obs.) }\end{array}$ & $\begin{array}{c}\text { Participation } \\
\text { ratio }\end{array}$ & \multicolumn{2}{|c|}{ Variance } & \multicolumn{2}{|c|}{$\begin{array}{c}\text { Equal } \\
\text { means }\end{array}$} \\
\hline FoodBev & 276 & 0.472 & 0.249 & & & \\
\hline Drugstore & 253 & 0.432 & 0.245 & & & \\
\hline Clothing & 219 & 0.374 & 0.234 & & & \\
\hline Shoes & 147 & 0.251 & 0.188 & & \\
\hline Electronics & 107 & 0.183 & 0.149 & & \\
\hline Home & 106 & 0.181 & 0.148 & & \\
\hline Cinema & 105 & 0.179 & 0.147 & & \\
\hline Restaurant & 93 & 0.159 & 0.134 & & & \\
\hline HobGard & 61 & 0.104 & 0.093 & & & \\
\hline Toys & 41 & 0.070 & 0.065 & & \\
\hline SmHo_App & 33 & 0.056 & 0.053 & & \\
\hline Home_App & 26 & 0.044 & 0.042 & & \\
\hline
\end{tabular}

The above described correlation-based analysis may provide a solid overview, yet it is limited by only taking into account the individual LP participation/nonparticipation records while ignoring all additional information from the survey. Hierarchical cluster analysis provides a a new layer of interpretation to the data. For our 12 product categories, the grouping of LP-participation into different clusters (groups) can be conveniently summarized into a tree-like picture - a dendrogram as in Figure 1. For interpretation, the number of clusters may be chosen arbitrarily. However, by considering both the clustering and product class perspectives, the dendrogram suggests four main product groups (similarity within group is defined by 
concurrent participation in LPs): a) Drugstore and Food \& Beverages, b) "Fashion" (Clothing and Shoes), c) "Home and family" (Home, Master and Small home appliances, Toys) and d) "Entertainment" (Electronics, Restaurant, Cinema). From the dendrogram, we can also see the hierarchical nature of the clustering output - from the leaves (individual product categories) to higher-level aggregation. At the corporate level, such information has significant value, as it shows the potential and limitations for synergic effects among LPs. Also, there are implications towards implementation of LPs in a multi-product category environment (brick-and-mortar, on-line, specialized and universal retail chains, etc.).

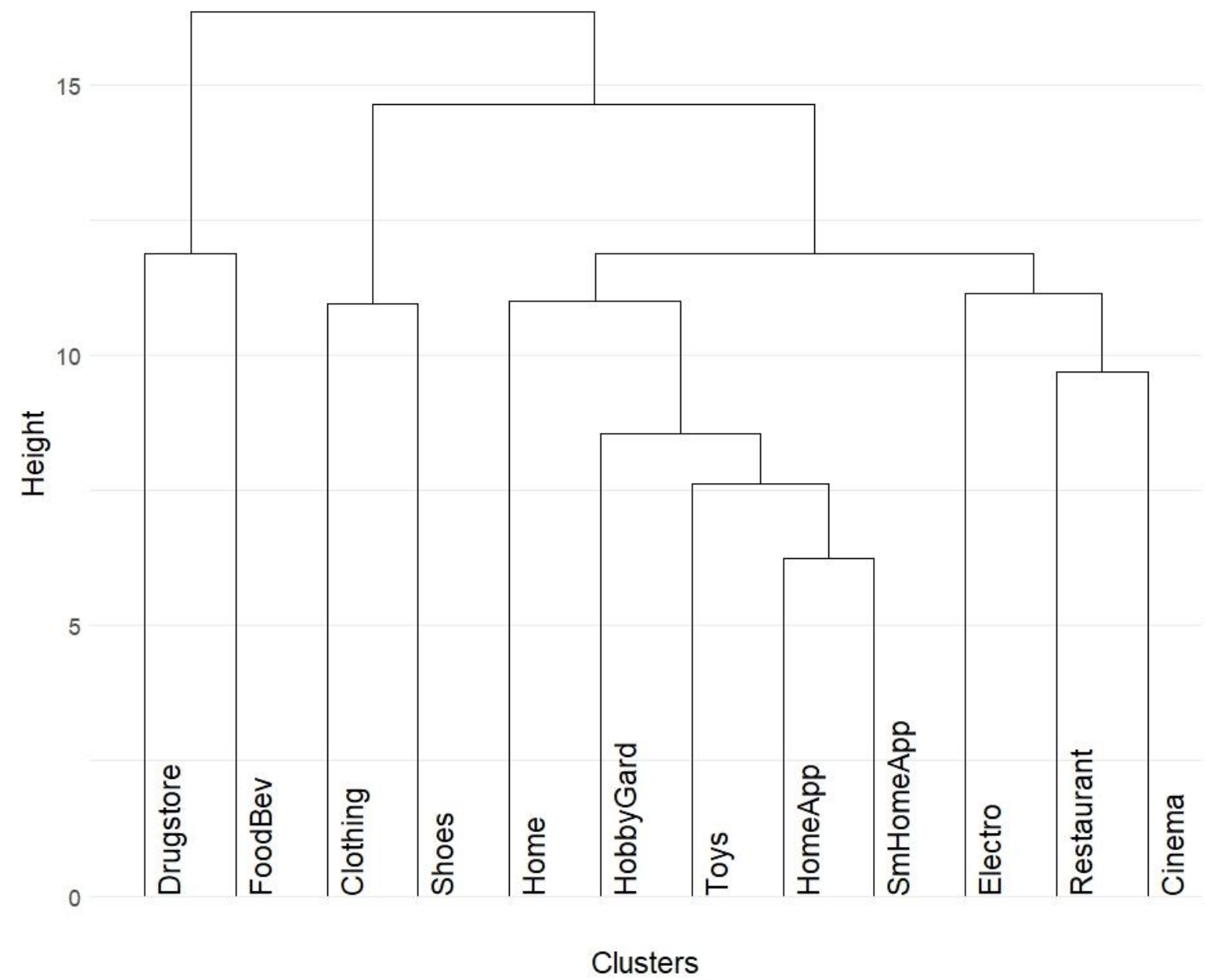

Figure 1. Dendrogram of LP participation clustering

Source: Authors' own research.

From Figure 1, we can see that the Master and Small home appliances product categories are the most similar (in terms of concurrent consumer participation) as their two branches are the first to merge. On the other side of this spectrum, participation patterns in the Drugstore and Food \& Beverages group are very dissimilar from all the remaining product categories considered. Given its nonparametric nature, clustering is not suitable for informative identification of different statistically significant factors of LP-participation among diverse consumer groups 
(defined by age, lifestyle or otherwise). Therefore, we turn our attention to logistic regression and related inference methods. Empirically, many minor and essentially random influences may play a significant role in individual LP-participation decisions, yet by means of logistic regression, we often are able to identify and quantify important statistically significant differences among distinct groups of consumers. We use model (1) specification for each of the twelve binaries describing LP-participation. All estimated models are statistically significant and provide reasonable prediction accuracy. Given the interpretability limitations related to the estimated $\beta$-coefficients from the logistic model (2), we focus on the APEs (heteroskedasticity consistent standard errors are provided in brackets). All signs and statistical significances in the APE values (Tables 2 and 3) may be unambiguously traced back to the estimated $\beta$ coefficients of model (1).

Table 2. Average partial effects (product categories 1-6)

\begin{tabular}{|c|c|c|c|c|c|c|}
\hline & FoodBev & Drugstore & Clothing & Shoes & Electro & Home \\
\hline \multirow[t]{2}{*}{ Gen_X } & 0.041 & $0^{0.138^{*}}$ & $0.132^{*}$ & 0.161* $^{*}$ & $0.137^{*}$ & 0.048 \\
\hline & $(0.052)$ & $(0.047)$ & $(0.047)$ & $(0.050)$ & $(0.048)$ & $(0.046)$ \\
\hline \multirow[t]{2}{*}{ Gen_Y } & $0.104^{*}$ & $0.128^{*}$ & $0.281^{*}$ & $0.239^{*}$ & 0.086 & 0.113* \\
\hline & $(0.059)$ & $(0.052)$ & $(0.052)$ & $(0.056)$ & $(0.055)$ & $(0.055)$ \\
\hline \multirow[t]{2}{*}{ Gen_Z } & -0.044 & $0.092^{\circ}$ & $0.217^{*}$ & $0.234^{*}$ & $0.141^{*}$ & 0.031 \\
\hline & $(0.062)$ & $(0.054)$ & $(0.057)$ & $(0.059)$ & $(0.061)$ & $(0.055)$ \\
\hline \multirow[t]{2}{*}{ Female } & $0.220^{*}$ & $0.402^{*}$ & $0.182^{*}$ & $0.172^{*}$ & $-0.131^{*}$ & 0.119* \\
\hline & $(0.040)$ & $(0.036)$ & $(0.036)$ & $(0.033)$ & $(0.031)$ & $(0.031)$ \\
\hline \multirow[t]{2}{*}{ Prague } & $0.145^{*}$ & $0.096^{\circ}$ & $0.139^{*}$ & $-0.088^{*}$ & -0.025 & 0.056 \\
\hline & $(0.062)$ & $(0.055)$ & $(0.059)$ & $(0.044)$ & $(0.044)$ & $(0.050)$ \\
\hline \multirow[t]{2}{*}{ EducUniv } & 0.054 & $0.122^{*}$ & $0.087^{\circ}$ & 0.055 & 0.043 & 0.039 \\
\hline & $(0.048)$ & $(0.045)$ & $(0.045)$ & $(0.041)$ & $(0.036)$ & $(0.037)$ \\
\hline \multirow[t]{2}{*}{ EarningsHigh } & 0.103 & 0.114 & $0.226^{*}$ & $0.381^{*}$ & 0.125 & 0.071 \\
\hline & $(0.081)$ & $(0.072)$ & $(0.077)$ & $(0.086)$ & $(0.079)$ & $(0.074)$ \\
\hline \multirow[t]{2}{*}{ LSnatureNo } & -0.067 & $-0.190^{*}$ & -0.017 & -0.010 & -0.054 & -0.001 \\
\hline & $(0.106)$ & $(0.087)$ & $(0.099)$ & $(0.089)$ & $(0.068)$ & $(0.085)$ \\
\hline \multirow[t]{2}{*}{ LS_TV_No } & -0.120 & $-0.146^{\circ}$ & $-0.251^{*}$ & $-0.110^{\circ}$ & -0.048 & $-0.108^{*}$ \\
\hline & $(0.088)$ & $(0.084)$ & $(0.056)$ & $(0.067)$ & $(0.061)$ & $(0.049)$ \\
\hline \multirow[t]{2}{*}{ LSfitnessYes } & 0.042 & 0.030 & $0.096^{\circ}$ & 0.067 & 0.054 & 0.035 \\
\hline & $(0.053)$ & $(0.051)$ & $(0.051)$ & $(0.047)$ & $(0.043)$ & $(0.043)$ \\
\hline \multirow[t]{2}{*}{ LSgreenfingYes } & -0.052 & $-0.087^{\circ}$ & $-0.113^{*}$ & -0.002 & $-0.084^{*}$ & -0.038 \\
\hline & $(0.055)$ & $(0.048)$ & $(0.050)$ & $(0.050)$ & $(0.041)$ & $(0.044)$ \\
\hline
\end{tabular}

Source: Authors' own research.

Although the estimation process is complex and the resulting output is very extensive, its analysis and interpretation is not difficult. We shall use the Drugstore product category (Table 2) to provide an interpretation example: If we focus on the generational aspects first, we can see that - on average - members of generation $\mathrm{Z}$ are

Vol.12, No. 4, Winter, pp. 524-539, ISSN 1842-0206 | Management \& Marketing. Challenges for the Knowledge Society 
$9.2 \%$ more likely to participate in a LP (Drugstore products) when compared to the reference group of Baby boomers and older. Similarly, members of generations Y and $\mathrm{X}$ are $12.8 \%$ and $13.8 \%$ more likely to participate in a LP, compared to Baby boomers and older (please note that APEs always relate to corresponding reference categories). This interpretation of expected (average) changes in participation probabilities has a ceteris paribus validity - i.e. it holds, given any individual characteristics as described by variables explicitly included in model (1), i.e. gender, domicile, lifestyle factors, etc.

Table 3. Average partial effects (product categories 7-12)

\begin{tabular}{|c|c|c|c|c|c|c|}
\hline & Cinema & Restaurant & HobGard & Toys & SmHoApp & HoАрp \\
\hline \multirow[t]{2}{*}{ Gen_X } & 0.176 $^{*}$ & $0.127^{*}$ & 0.018 & $0.097^{*}$ & $0.067^{*}$ & 0.011 \\
\hline & $(0.051)$ & $(0.049)$ & $(0.031)$ & $(0.042)$ & $(0.034)$ & $(0.025)$ \\
\hline \multirow[t]{2}{*}{ Gen_Y } & $0.323^{*}$ & 0.180* & -0.003 & 0.023 & 0.021 & 0.015 \\
\hline & $(0.055)$ & $(0.057)$ & $(0.035)$ & $(0.042)$ & $(0.034)$ & $(0.027)$ \\
\hline \multirow[t]{2}{*}{ Gen_Z } & $0.347^{*}$ & $0.154^{*}$ & $-0.105^{*}$ & 0.021 & -0.011 & -0.008 \\
\hline & $(0.063)$ & $(0.060)$ & $(0.020)$ & $(0.042)$ & $(0.028)$ & $(0.023)$ \\
\hline \multirow[t]{2}{*}{ Female } & 0.041 & 0.010 & -0.022 & $0.039^{\circ}$ & -0.017 & $0.032^{\circ}$ \\
\hline & $(0.030)$ & $(0.028)$ & $(0.025)$ & $(0.021)$ & $(0.018)$ & $(0.018)$ \\
\hline \multirow[t]{2}{*}{ Prague } & 0.003 & 0.046 & $-0.058^{\circ}$ & -0.007 & 0.051 & -0.025 \\
\hline & $(0.047)$ & $(0.048)$ & $(0.031)$ & $(0.033)$ & $(0.042)$ & $(0.018)$ \\
\hline \multirow[t]{2}{*}{ EducUniv } & 0.034 & $0.080^{*}$ & 0.010 & -0.021 & 0.016 & 0.006 \\
\hline & $(0.036)$ & $(0.035)$ & $(0.034)$ & $(0.024)$ & $(0.023)$ & $(0.02)$ \\
\hline \multirow[t]{2}{*}{ EarningsHigh } & $\mathbf{0 . 1 7 3}^{*}$ & $0.182^{*}$ & $-0.110^{*}$ & 0.012 & -0.002 & 0.057 \\
\hline & $(0.082)$ & $(0.073)$ & $(0.013)$ & $(0.044)$ & $(0.034)$ & $(0.053)$ \\
\hline \multirow[t]{2}{*}{ LSnatureNo } & 0.093 & -0.067 & -0.003 & 0.115 & 0.035 & 0.073 \\
\hline & $(0.089)$ & $(0.062)$ & $(0.068)$ & $(0.081)$ & $(0.062)$ & $(0.065)$ \\
\hline \multirow[t]{2}{*}{ LS_TV_No } & -0.006 & -0.069 & 0.028 & -0.024 & -0.006 & -0.021 \\
\hline & $(0.064)$ & $(0.048)$ & $(0.070)$ & $(0.046)$ & $(0.041)$ & $(0.028)$ \\
\hline \multirow[t]{2}{*}{ LSfitnessYes } & 0.022 & 0.048 & $-0.057^{\circ}$ & -0.027 & $0.052^{\circ}$ & $0.066^{*}$ \\
\hline & $(0.038)$ & $(0.039)$ & $(0.032)$ & $(0.025)$ & $(0.032)$ & $(0.029)$ \\
\hline \multirow[t]{2}{*}{ LSgreenfingYes } & $-0.145^{*}$ & $-0.144^{*}$ & $0.068^{-}$ & $-0.039^{\circ}$ & $\begin{array}{l}-0.008 \\
\end{array}$ & -0.024 \\
\hline & $(0.032)$ & $(0.027)$ & $(0.036)$ & $(0.024)$ & $(0.025)$ & $(0.018)$ \\
\hline
\end{tabular}

Source: Authors' own research.

Similarly, female consumers are $40.2 \%$ more likely to participate in Drugstorerelated LPs when compared with males (the reference group). Prague domicile and university education also play an important role, adding $9.6 \%$ and $12.2 \%$ respectively to ceteris paribus LP-participation probabilities. Turning to lifestyle factors, we can see that individuals who dissociate themselves from being fond of taking trips/walks in nature (LSnatureNo variable) are also $19 \%$ less likely to participate in a Drugstore-LP when compared to the reference - people who like such trips combined with individuals without a strong position on this subject.

Vol. 12, No.4, Winter, pp. 524-539, ISSN 1842-0206 | Management \& Marketing. Challenges for the Knowledge Society 
Respondents who dissociate themselves from watching TV are also $14.6 \%$ less likely to be LP members (Drugstore products). In an interesting conjunction, gardening (LSgardeningYes) is also associated with some $8.7 \%$ decrease in Drugstore-LP participation. Finally, belonging to a high-earnings household or doing sports \& fitness are not statistically relevant in terms of LP-participation for the Drugstore category. In a similar way, APE results (Tables 2 and 3) may be examined and interpreted for each product category. We skip such rather routine and lengthy approach - instead, some of the most interesting findings (differences and similarities in LP-participation) are highlighted and discussed next.

Generationally speaking, $\mathrm{X}, \mathrm{Y}$ and Z-generation members are always more likely to participate in LPs in all product categories, with the sole exception of Hobby \& garden, where the youngest generation $(\mathrm{Z})$ is $10.5 \%$ less likely to participate as compared to the reference (Baby boomers and older). Generational differences are most striking for the Cinema category $(+34.7 \%$ in participation probability for generation Z) and they are quite high for the Clothing and Shoes categories. Interestingly, generation Y members are the ones most likely to participate in LPs for Clothing and Shoes, with $28.1 \%$ and $23.9 \%$ respective increases in probabilities. Also, Female consumers are more likely to be LP members in every product category (Table 2 ), with the rather striking exception of Electronics, where their participation probability decreases by $13.1 \%$ (interpretation is performed ceteris paribus, i.e. while controlling for age, lifestyle and other characteristics included in the model).

University degree has a limited impact on LP membership - it increases participation probability for the Drugstore category (+12.2\%) and has some positive effect on Clothing and Restaurant LPs: $+8.7 \%$ and $+8 \%$. High earning individuals (members of high-earning households) tend to participate more in Clothing and Shoes $(+22.6 \%$ and $+38.1 \%)$ as well as in Cinema and Restaurant categories, while being less likely to join a LP in the Hobby \& garden segment (- $11 \%)$. As far as lifestyle factors are concerned, people who strongly dissociate themselves from watching TV are also less likely to be LP members in every single category, where this factor is statistically significant. The most prominent difference may be observed for Clothing, where $L S_{-} T V_{-} N o_{i}=1$ is associated with a $25.1 \%$ decrease in LP participation probability. Active gardening and fruit/vegetable growing (LSgardeningYes) is also associated with decreases in LP-participation probabilities across all product categories where this factor is significant ( 6 categories), with an obvious exception of the Hobby \& garden products segment.

Next, we turn our attention to the combined effects of age (generation groups) and gender. Individual interaction elements as described in the preceding section are not easily interpretable in terms of APEs (Table 2 and 3). This comes from the fact that higher-order terms (interaction elements such as gen_Z $Z_{i} \times$ Female $_{i}$ ) must be combined - interpreted together - with their lower-order constituents (main effects). For the effects display approach as in Figure 2, main effects are absorbed into the higher-order terms, thus allowing our predictions to consistently vary over their ranges (two levels for Female F $_{i}$ and four generational levels for the Age_code "factor" $^{\prime}$ variable), while the values of other predictors are fixed at convenient representative values (means, medians, etc.). Please note the non-symmetric nature of the effects' 95 $\%$ confidence intervals that reflect the $\langle 0,1\rangle$ ranges of response variables Vol. 12, No. 4, Winter, pp. 524-539, ISSN 1842-0206 | Management \& Marketing. Challenges for the Knowledge Society 
(probabilities of LP-participation in selected product categories). Display effects are only shown (Figure 2) for the four categories (a) to (d) as described in the Data handling section. Product categories with lower LP-participation rates are omitted from this figure, as the confidence intervals tend to grow considerably for the estimated participation probabilities in categories with low overall LP penetration rates (hence the interpretation benefits do not outweigh space availability considerations).
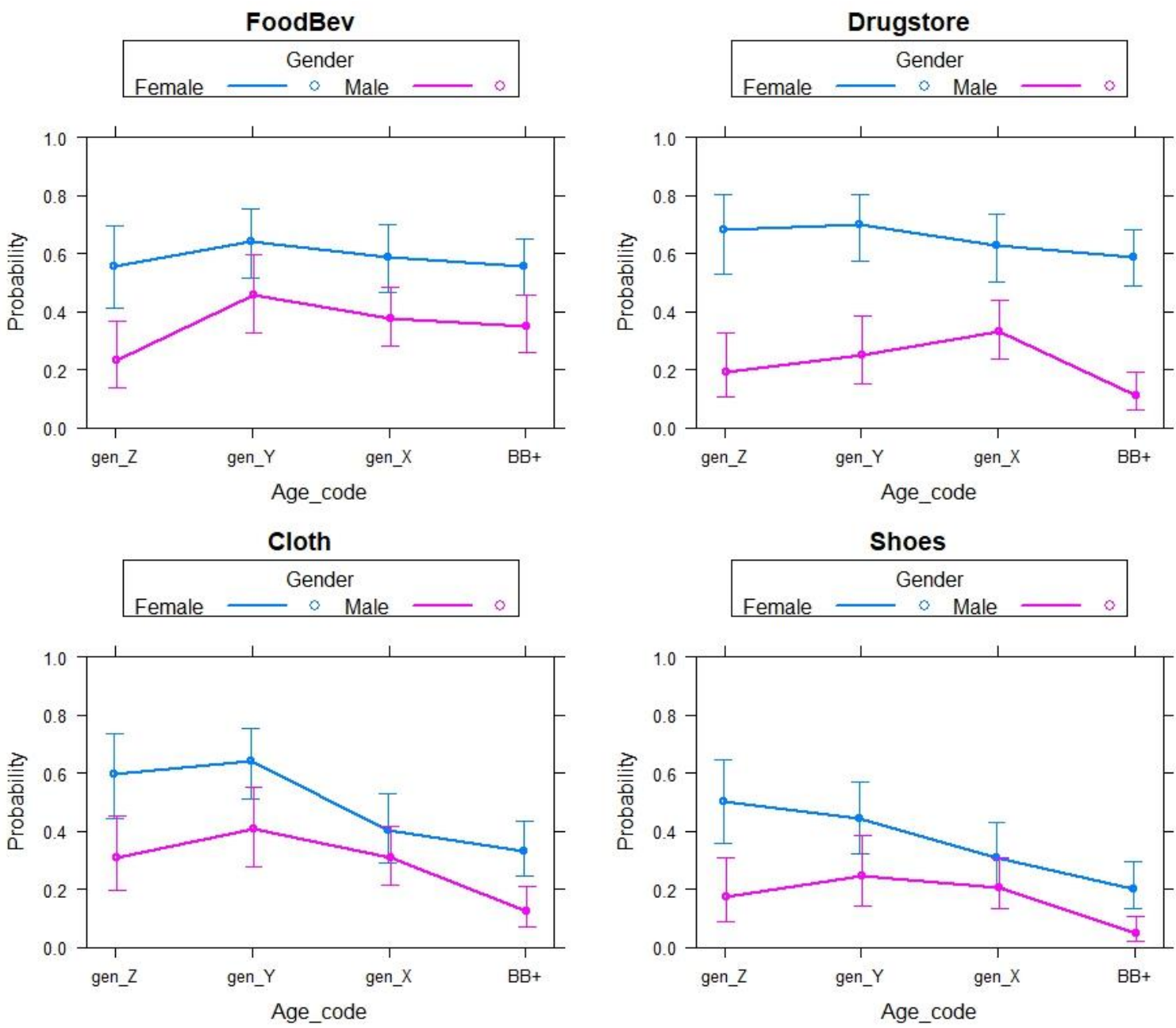

Figure 2. Display effects of gender and age on LP-participation probabilities

Source: Authors' own research.

From the display effects, we may see that female consumers tend to participate in LPs noticeably more than males. This difference is biggest for generation $\mathrm{Z}$ members and - generally speaking - it tends to decrease for older age groups (generations). Male LP-participation rates reach maxima for individuals belonging to generations $\mathrm{X}$ and $\mathrm{Y}$. For female consumer, the picture is quite different: LPparticipation steadily decreases with growing age for the Shoes category. For the Clothing products, female probability of LP membership increases slightly from 
generation $\mathrm{Z}$ to $\mathrm{Y}$ and then it drops relatively sharply from generation $\mathrm{X}$ to Baby boomers and older. For Food \& beverages and Drugstore categories, there is not a distinct observable trend (especially if we take into account the confidence intervals), yet peak participation probabilities are associated with generation $Y$ female members.

\section{Conclusion}

Today's marketing professionals constantly search for innovative ways of addressing and attracting new customers, as well as retaining them and gaining their loyalty. In this article, we have identified product category clusters for which consumers tend to participate in loyalty programs concurrently. Adequate product category clustering and appropriately adjusted positioning can bring forward profitable advantages and multiplicative benefits when compared with other loyalty program settings (say, only related to a single manufacturer or a particular brand). The identified similarities and distinctive properties of consumer behavior can be used by manufacturers and retailers alike. Marketing professionals in the field of on-line and brick-and-mortar retail operations can set up loyalty program parameters more accurately and create convenient product category clusters.

The first cluster consists of Drugstore and Food \& beverages categories. Those products are mostly associated with basic household operations and closely interrelated by means of concurrently participating similar consumers. Generational differences in loyalty program participation are negligible in this cluster, yet female consumers are significantly more likely to participate. This cluster has the highest overall participation ratio. The second cluster consists of Clothing and Shoes product categories, with a clear thematic connection between them. The overall participation is relatively high: $37 \%$ and $25 \%$ respectively. Here, high earning individuals and even more prominently - female consumers from the $\mathrm{Z}$ and $\mathrm{Y}$ generations are significantly more likely to participate in loyalty programs.

Our analysis also reveals a third cluster of product categories with a pronounced tendency toward concurrent use: Home, Hobby \& gardening, Toys, Master home appliances and Small home appliances. Here, overall loyalty program participation rates are rather low (5\% to 9\%) and generational differences are less pronounced, yet generation $\mathrm{X}$ members tend to participate more and certain lifestyle preferences also play significant roles. The last cluster includes the Electronics, Cinema and Restaurant categories, with participation rates between $16 \%$ and 18\%. In this cluster, typical loyalty program users belong to the $\mathrm{Y}$ and $\mathrm{Z}$ generations, yet gender, earnings and several lifestyle preferences play important roles.

Overall, we have outlined loyalty program participation clusters along with important factors influencing individual propensities to loyalty program participation. Opportunities and limitations of co-branding programs are presented, along with statistically relevant information that may be used for fine tuning loyalty programs and participation incentives. Our research shows that generational differences significantly determine consumer behavior. The incoming $\mathrm{Y}$ and Z-generation consumers have different attitudes towards loyalty programs when compared to older generational cohorts. Our follow-up research shall focus on the generational vs. human lifecycle differences and dynamics in consumer behavior. 


\section{Acknowledgement}

Supported by the grant No. IGA F4/58/2017, Faculty of Informatics and Statistics, University of Economics, Prague.

\section{References}

Aaker, D.A. (2009), Managing brand equity, Simon and Schuster, New York.

Bauer, M. and Auer-Srnka, K. (2012), "The life cycle concept in marketing research", Journal of Historical Research in Marketing, Vol. 4, No. 1, pp. 68-96.

Bilgihan, A., Cheng, P. and Kandampully, J. (2014), "Generation Y's dining information seeking and sharing behavior on social networking sites", International Journal of Contemporary Hospitality Management, Vol. 26, No. 3, pp. 349-366.

DuWors, R.E. and Haines, G.H. (1990), "Event history analysis measures of brand loyalty.", JMR, Journal of Marketing Research, Vol. 2, No. 4, p. 485.

Chaudhuri, A. and Holbrook, M.B. (2001), "The chain of effects from brand trust and brand affect to brand performance: The role of brand loyalty", Journal of Marketing, Vol. 65, No. 2, pp. 81-93.

Chung, C.W. and Hsu, J.J. (2012), "Application of Life Style Model to Analyze the Market of Department Stores", Journal of Service Science and Management, Vol. 5, No. 3, pp. 302-311.

Craft, S.H. (1999), "Marketers gain by measuring true loyalty", Marketing News, Vol. 33, No. 10, pp. 18-18.

Formánek, T. and Tahal, R. (2016), "Brand importance across product categories in the Czech Republic", Management \& Marketing. Challenges for the Knowledge Society, Vol. 11, No. 1, pp. 341-354.

Fox, J. and Hong, J. (2009), "Effect Displays in R for Multinomial and ProportionalOdds Logit Models: Extensions to the effects Package", Journal of Statistical Software, Vol. 32, No. 1, pp. 1-24.

Gibbons, J.D. and Chakraborti, S. (2003), Nonparametric Statistical Inference, $4^{\text {th }}$ edition, CRC Press, Berlin Heidelberg.

Gordon, A.D. (1999), Classification, $2^{\text {nd }}$ edition, Chapman and Hall/CRC, London.

Hastie, T., Tibshirani, R. and Friedman, J.H. (2009), The elements of statistical learning: Data mining, inference, and prediction, $2^{\text {nd }}$ edition, Springer-Verlag, New York.

Hem, L.E. and Iversen, N.M. (2002), "Transfer of brand equity in brand extensions: The importance of brand loyalty", Advances in Consumer Research, Vol. 30, pp. 7279.

Loroz, P.S. and Helgeson, J.G. (2013), "Boomers and their babies: an exploratory study comparing psychological profiles and advertising appeal effectiveness across two generations", Journal of Marketing Theory and Practice, Vol. 21, No. 3, pp. 289-306.

Maity, M. and Gupta, S. (2016), "Mediating effect of loyalty program membership on the relationship between advertising effectiveness and brand loyalty", Journal of Marketing Theory and Practice, Vol. 24, No. 4, pp. 462-481. 
Macías, W. and Cerviño, J. (2017), "Trademark dilution: comparing the effects of blurring and tarnishment cases over brand equity", Management \& Marketing. Challenges for the Knowledge Society, Vol. 12, No. 3, pp. 346-360.

Meyer-Waarden, L. (2008), "The influence of loyalty programme membership on customer purchase behavior", European Journal of Marketing, Vol. 42, pp. 87114.

Oliver, R.L. (1999), “Whence consumer loyalty?”, The Journal of Marketing, Vol. 63, No. 1, pp. 33-44.

Omar, N.A., Che, A.C.W., Norzalita, A.A. and Syed, S.A. (2013), "Investigating the structural relationship between loyalty programme service quality, satisfaction and loyalty for retail loyalty programmes: Evidence from Malaysia", Measuring Business Excellence, Vol. 17, No. 1, pp. 33-50.

Pourmand, J. and Lari, M.A. (2016), "The study of relationship management with electronic customer on the quality of customer relationship in Mellat bank", International Journal of Education and Management Studies, Vol. 6, No. 3, pp. 300-304.

Roberts, J.A. and Manolis, C. (2000), "Baby boomers and busters: An exploratory investigation of attitudes toward marketing, advertising and consumerism", The Journal of Consumer Marketing, Vol. 17, No. 6, pp. 481-499.

Rowley, J. (2007), "Reconceptualising the strategic role of loyalty schemes", The Journal of Consumer Marketing, Vol. 24, No. 6, pp. 366-374.

Roy, S., Guha, A. and Biswas, A. (2015), "Celebrity endorsements and women consumers in India: How generation-cohort affiliation and celebrity-product congruency moderate the benefits of chronological age congruency", Marketing Letters, Vol. 26, No. 33, pp. 363-376.

Shahzad, F., Khattak, J.K., Khattak, M.J. and Shahzad, F. (2015), "Impact of consumer socialization on soft drink consumption and mediating role of consumer generational behavior", British Food Journal, Vol. 117, No. 3, pp. 1205-1222.

Tahal, R., Formánek, T. and Mohelská, H. (2017), "Loyalty Programs and Personal Data Sharing Preferences in the Czech Republic", E\&M. Economics and Management, Vol. 20, No. 1, pp. 187-199.

Voinea, L., Popescu, D.V. and Negrea, M.T. (2015), "Good practices in educating and informing the new generation of consumers on organic foodstuffs", Amfiteatru Economic, Vol. 17, No. 38, pp. 488-506.

Williams, K.C., Page, R.A., Petrosky, A.R. and Hernandez, E.H. (2010), "Multigenerational marketing: Descriptions, characteristics, lifestyles, and attitudes", The Journal of Applied Business and Economics, Vol. 11, No. 2, pp. 21-36.

Wooldridge, J.M. (2010), Econometric Analysis of Cross Section and Panel Data, 2nd edition, MIT Press, Cambridge.

Yoo, M. (2011), "The long-term impact of a loyalty program: An evaluation from a Las Vegas casino hotel", UNLV Theses, Dissertations, Professional Papers, and Capstones. Retrieved from http://digitalscholarship.unlv.edu/thesesdiss ertations/1271 (accessed September 20, 2017). 